\title{
A TECNOLOGIA COMO ALIADA NO ENSINO DE HISTÓRIA E A SUA ADESÃO NAS ESCOLAS DE EDUCAÇÃO BÁSICA
}

\author{
Hilda Maria Gonçalves da SILVA ${ }^{1}$ \\ Célia Maria DAVID ${ }^{2}$ \\ Almir MANTOVANI ${ }^{3}$
}

RESUMO: A pesquisa em tela teve como objetivo apreender a inserção das TICs tecnologias de informação e comunicação - na ação docente da rede pública de ensino básico do estado de São Paulo, mais especificamente em relação ao ensino de História. Elaborou-se uma contextualização histórica do amparo ao uso dessas tecnologias nas instituições de ensino. A amostragem, dos dados levantados sobre a utilização desses recursos, teve como recorte a cidade de Franca e contou com a colaboração dos graduandos do quarto ano do curso de História da Unesp-Franca. Apreende-se da análise que apesar da extensa bibliografia que versa sobre os benefícios da utilização dos recursos tecnológicos para o ensino de História nas aulas de educação básica e, ainda da forte defesa em relação ao uso desses recursos pela Secretaria de Educação do Estado de São Paulo; a realidade prática das instituições de ensino ainda encontra-se enraizada em um processo educativo que se restringe, essencialmente, a figura do professor e ao livro didático, ou aos cadernos de aprendizagem fornecidos pelo Estado.

PALAVRAS-CHAVE: Educação. Tecnologia. Prática docente.

\section{Introdução}

O acelerado processo de globalização ocorrido nas últimas décadas, promovido, fundamentalmente, pelo avanço tecnológico, pelo desenvolvimento da microeletrônica e dos sistemas de telecomunicação, trouxe como uma de suas consequências a intensificação das relações sociais em níveis mundiais jamais imaginados anteriormente (GUIDDENS, 1991).

Esse processo deslocou as barreiras espaciais de acesso à informação e à comunicação, tendo como resultado a redução do espaço/tempo e a ampliação da

${ }^{1}$ Professora Doutora do Departamento de Educação, Ciências Sociais e Políticas Públicas e dos cursos de Pós-Graduação em Planejamento e Análise de Políticas Públicas e de Serviço Social. UNESP Universidade Estadual Paulista, campus Franca. Franca - SP - Brasil. 14409-160 hilda_gs@yahoo.com.br.

${ }^{2}$ Professora Adjunta do Departamento de Educação, Ciências Sociais e Políticas Públicas e dos cursos de Pós-Graduação em Planejamento e Análise de Políticas Públicas e de Serviço Social. UNESP Universidade Estadual Paulista, campus Franca. Franca - SP - Brasil. 14409-160 cmdavid@hotmail.com.br.

${ }^{3}$ Professor Doutor do Departamento de Educação, Ciências Sociais e Políticas Públicas. UNESP Universidade Estadual Paulista, campus Franca. Franca - SP - Brasil. 14409-160 a_almirr@yahoo.com.br. 
velocidade de sua circulação de tal ordem que esse fenômeno ficou conhecido como “encolhimento do mundo" (HARVEY, 1992).

Essa nova dinâmica de acesso, de relação com a informação e de modo mais complexo com o conhecimento na sociedade atual levou alguns estudiosos do tema a afirmarem que estamos diante da "sociedade do conhecimento". Cardoso (1996) ao tratar desse advento, faz os seguintes apontamentos:

A aplicação do conhecimento científico a situações empíricas redundou no rápido desenvolvimento de tecnologias, complexificando cada vez mais os processos produtivos de bens e serviços, em uma dinâmica auto-alimentadora, na qual cada mudança tecnológica engendra necessidades e imperativos que são, por sua vez, detonadores de outras soluções e produtos, indefinidamente. Chegamos então a chamada "sociedade do conhecimento", termo significante de uma situação social, sobre a qual pode ser feita a analogia com a acumulação de capital financeiro necessária ao desenvolvimento da industrialização: assim como o acúmulo de dinheiro permitiu o investimento em fábricas e maquinarias, na fase atual o recurso produtivo mais importante passa a ser o conhecimento estocado; seu acúmulo permite o avanço tecnológico, a flexibilização da produção e a segmentação do consumo. (CARDOSO, 1996, p.66).

Desse modo, investir em educação tornou-se condição sine qua non para os países que lograssem alcançar a competitividade econômica internacional e a redução das desigualdades sociais. E mais ainda era necessário investir em uma educação que inserisse o Brasil nessa perspectiva da "sociedade do conhecimento", ou seja, na dinâmica complexa que envolvia toda a transformação trazida pelo anuncio da era digital.

Nesse contexto, o Brasil se encontrava numa situação bastante desfavorável, uma vez que o índice médio de escolarização da população não alcançava cinco anos na década de 1980 e o analfabetismo ultrapassava a marca dos $30 \%$ da população.

Esse contexto histórico coincide ainda no Brasil com o processo de redemocratização do país, marcado pela promulgação da Constituição de 1988 que ficou conhecida como Constituição "Cidadã”, pois trouxe em seu bojo diversos avanços em relação aos direitos sociais e humanos.

Em relação ao direito à educação, inserido no âmbito mais amplo dos direitos sociais na Carta Magna, ao menos três aspectos merecem destaque:

- a educação nos diversos níveis foi reconhecida como responsabilidade do Estado e da família;

- o caráter de gratuidade da educação pública nos diversos níveis; 
- a preocupação em conferir um padrão de qualidade à educação, mesmo este não estando muito claro.

Passados mais de vinte anos da promulgação da Constituição brasileira, alguns direitos à educação, por ela proclamados ainda não foram totalmente concretizados. Um exemplo disto é a média de escolarização da população que, embora tenha crescido significativamente alcançando 7,3 anos entre os maiores de 24 anos, não chegou aos oito anos declarados pela Carta Magna.

Ademais, o acesso à informação e ao conhecimento, hoje, está extremamente relacionado ao acesso às novas tecnologias, desse modo, "mecanismos que filtram ou restringem o acesso à informação" se configuram como "uma violação do direito universal" de comunicação e de acesso à educação. Nesse sentido, torna-se crucial constituir políticas públicas que efetivamente garantam o acesso digital de forma equitativa (BURUNI, 2005).

Esse acesso inclui, além do recurso material, saber apropriar-se desse mundo digital, o que remete, mais uma vez, à educação. Para ficar somente no acesso material, os domicílios brasileiros que possuem computadores com acesso à internet, hoje, não chegam a 50\%, os dados do IBGE de 2013 (BRASIL, 2013), mostram, ainda, que 53\% da população não tem qualquer tipo de acesso à internet.

Assim, a concretização do artigo 205 da nossa Carta Magna, "educação, direito de todos [...], visando ao pleno desenvolvimento da pessoa, seu preparo para o exercício da cidadania e sua qualificação para o trabalho" (grifo nosso) (BRASIL, 1988) ainda está longe de se tornar uma realidade. Muitos são os aspectos que concorrem para essa concretização. No âmbito das políticas educacionais, como afirma Palma Filho (2010):

Para que a intenção do legislador se torne realidade é necessário que os responsáveis pela condução da política educacional em âmbito nacional, estadual e municipal criem condições para o efetivo cumprimento do que dispõe a Constituição Federal, a LDB e o Plano Nacional de Educação.

Importante, nesse ponto, insistir que para além dos aspectos mais gerais as mudanças promovidas pelo avanço tecnológico descritos nas linhas acima, trazem consigo a questão mais específica da significativa transformação sobrevinda na dinâmica que envolve a busca e a construção do conhecimento. Ora, essa transformação impacta diretamente nas questões pedagógicas que envolvem a formação dos sujeitos. 
As tecnologias hoje são ferramentas importantes na vida dos sujeitos, de tal sorte que conforme viemos balizando, a exclusão digital tem forte impacto na inserção social.

Nessa perspectiva, torna-se imprescindível o uso das tecnologias de comunicação e informação nas escolas públicas de educação básica, quando se busca atender a "algum" padrão de qualidade. Lévy (1993) ao declarar a existência de três categorias de conhecimento, a saber: a oral, a escrita e a digital; demonstra que, na sociedade atual, a ausência de uma dessas categorias restringe a inserção social do individuo e o seu acesso à cidadania. Isso porque essas três formas de apropriação do conhecimento apresentam particularidades no que diz respeito à complexidade das ações, às formas de pensar e de representar a realidade enfim ao acesso aos meios de inserção social.

As categorias escrita e digital, surgidas em tempos diferentes, promoveram mudanças determinantes na constituição das sociedades. Objeto desta pesquisa, a categoria digital, a mais recente, surgida do aperfeiçoamento tecnológico promoveu alterações decisivas no espaço/tempo, isto é, "transformou o modo como nós dispomos, compreendemos e representamos o tempo e o espaço em nossas relações cotidianas." (KENSKI, 2003, p.31).

Não se pode ignorar a relevância das alterações trazidas pelas Tic's, quando se trata de conferir qualidade ao processo de ensino-aprendizagem. Para além do uso puro e simples de novos equipamentos, o conhecimento digital, ao qual se refere Lévy (1993), promoveu novas formas de construção e de apropriação do conhecimento, surgindo daí uma outra (uma nova variação do) forma de organizar o conhecimento, a qual reivindica uma adequação do processo de ensino-aprendizagem.

A concretização do uso das Tic's na educação básica começa pela necessidade da construção de uma estrutura que garanta de fato o acesso a essas ferramentas. Ou seja, é imprescindível equipar as escolas com computadores, acesso à internet e sistemas de redes, softwares atualizados entre outros. Mas, a infraestrutura se configura apenas como o primeiro passo, a escola precisa ter um projeto pedagógico e uma equipe que adote o conhecimento digital como parte do processo de formação dos alunos. Faz-se necessário que esse seja um projeto da escola e de cada professor.

\section{As tecnologias de informação e comunicação e o ensino de História}


O ensino de História apresenta uma dinamicidade característica do fazer histórico, o qual se encontra constituído, principalmente, pelo diálogo entre o passado e o presente. A construção histórica, enquanto representação de um acontecimento, de uma conjuntura de uma realidade, não é estática, está em constante mutação.

A representação que a História constrói das feições do passado, consideradas relevantes, estão sujeitas às transformações, às quebras de paradigmas características da dinâmica da construção do conhecimento científico. E como não poderia deixar de ser a História ensinada na educação básica também sofre a influencia dessa dinâmica, não numa transposição pura e simples, mas pela interação das legitimações presente nas dimensões acadêmica e escolar.

As transformações tecnológicas trazidas pelas últimas décadas, bem como seus reflexos na educação formal, apresentam para o professor de História o desafio de além de possuir e ter consciência do domínio do conhecimento historiográfico em sua dinamicidade acadêmica (já que este deveria ser premissa da profissão), ser capaz de assumir o papel de articulador na interlocução com os alunos e desses com o saber histórico, construindo sentidos que garantam uma real apropriação do conhecimento. Para Schmidt (2002, p.57):

A aula de História é o momento em que, ciente do conhecimento que possui, o professor pode oferecer a seu aluno a apropriação do conhecimento histórico existente, através de um esforço e de uma atividade com a qual ele edificou esse conhecimento. [...] A sala de aula não é apenas um espaço onde se transmite informações, mas onde uma relação de interlocutores constroem sentidos. Trata-se de um espetáculo impregnado de tensões em que se torna inseparável o significado da relação teoria e prática, ensino e pesquisa. Na sala de aula se evidencia, de forma mais explícita, os dilaceramentos da profissão de professor e os embates da relação pedagógica.

Esse desafio no ensino da História implica, ainda e não menos, trazer para a sala de aula os novos espaços de busca desse conhecimento, ou seja, aqueles espaços próprios da categoria digital que se relacionam com as novas possibilidades de produção, apropriação e transmissão do saber histórico.

Muitas são as ferramentas que podem contribuir na construção dessa nova perspectiva teórico-prática para o ensino de História. Entre elas pode-se destacar: os artigos, as cartas, as reportagens, as obras de arte, os filmes e documentários, a música.

Esses instrumentos não são novidades de fato, muitos existem desde meados do século XX, outros são ainda bem anteriores. A novidade é que o avanço tecnológico permite hoje acessar todos esses instrumentos em alguns clicks, ou seja, é possível 
trabalhar com toda essa diversidade de formas de leitura da História, sem sair da sala de aula e, ainda, em se utilizando de sistemas de rede, debater, receber informações e trocar experiências com grupos diversificados.

Todo esse aparato permite adotar uma outra perspectiva de espaço/tempo na sala de aula, bem como, de possibilidade de utilização de documentos, tão cara ao ensino de História. Muitos documentos, como algumas obras de arte, por exemplo, seriam praticamente de impossível utilização, sem os recursos da informática. Isso, sem mencionar, o volume de material que o professor teria que transportar para trabalhar com boa parte desses instrumentos. Corroboramos com as palavras de Silva e Fonseca (2007, p.111):

É preciso pensar sobre algumas perspectivas básicas no contato com a informática no campo do conhecimento histórico, tanto na pesquisa, quanto no ensino e na aprendizagem. As redes de comunicação colocam professores e alunos em contato permanente com catálogos de museus, arquivos, e bibliotecas, bem como com textos e imagens pertencentes a esses acervos e sites que oferecem informações e análises de diferentes tópicos daquela área do saber. Além disso, os computadores permitem acumular informações e processá-las de diferentes formas, ampliando enormemente as possibilidades de acesso aos dados. Por fim, os grupos de discussão e outras comunidades da internet viabilizam compartilhar saberes e trocar interpretações com pessoas que, muitas vezes, estão fisicamente longe da sala de aula ou do laboratório de pesquisa.

Todas essas possibilidades trazidas pelas Tic's já se configurariam como argumentos irrefutáveis da importância da sua utilização para o ensino de História, contudo, cumpre destacar um aspecto fundamental dessas ferramentas, o qual retoma a concepção de Lévy (1993), já mencionada, sobre a categoria digital como uma nova forma de conhecimento.

Em História isso implica dizer que a música de protesto de Chico Buarque, não me diz mais sobre o momento histórico da ditadura presente nos livros didáticos, ela me diz outra coisa, do mesmo modo que uma visita virtual pelas coleções de artefatos do Egito antigo, no museu do Louvre, me traz outras impressões daquela civilização que não as trazidas pela leitura de textos que abordam o tema, ou pela explanação do professor.

Em suma, o que se defende nesse artigo em relação ao ensino de História é, a diversificação da atividade de sala de aula, mantendo a preocupação com a assimilação dos conceitos históricos básicos, mas integrando a categoria digital de conhecimento ao 
trabalho docente, num exercício de reconhecimento e apropriação da complexidade que constitui a prática docente do século XXI, articulando as categorias de conhecimento oral, escrito e digital.

\section{O (des)uso das Tic's nas aulas de História das escolas públicas estaduais de Franca}

A cidade de Franca possui 55 escolas estaduais de educação básica, das quais 40 atendem alunos dos ciclos finais do Ensino Fundamental e/ou do Ensino Médio.

O levantamento dos dados para a análise da utilização das tecnologias nas salas de aula de História contou com a colaboração dos alunos do $4^{\circ}$ ano do curso de História (ano de 2013) da Faculdade de Ciências Humanas e Sociais da Unesp-Franca.

Os alunos estiveram em 20 escolas da rede pública estadual de ensino durante o segundo semestre de 2013, observando as aulas de História nos anos finais do Ensino Fundamental e no Ensino Médio.

Cumpre esclarecer que a análise in loco centrou-se na verificação da intensidade do uso das tecnologias de informação e comunicação, pelos professores de História da educação básica de Franca. Desse modo, a apreensão da qualidade do uso dessas ferramentas, bem como, dos motivos da não utilização das mesmas, não se configuraram como objetos específicos desta análise.

O levantamento dos dados demonstrou que ao longo do segundo semestre de 2013, aproximadamente $80 \%$ dos professores de História das escolas analisadas utilizou como recurso didático em suas aulas somente o Caderno do Aluno e/ou o livro didático. Compete explicar que o Caderno do Aluno, consiste em um conjunto de apostilas distribuídas pela Secretaria de Educação a todos os alunos dos ciclos finais do Ensino Fundamental e do Ensino Médio, da rede estadual paulista.

Esse dado demonstra que apenas $20 \%$ dos docentes participantes da pesquisa utilizaram, em algum momento das aulas observadas, ferramentas didáticas como documentos, filmes, músicas, sistema de redes etc.

Observou-se ainda que em todas as escolas visitadas os materiais utilizados regularmente nas aulas de História são os livros, os Cadernos dos Alunos e/ou o Power Point. O uso dos demais recursos - filmes, músicas, internet etc. - é esporádico, mesmo entre aqueles $20 \%$ que lançam mão deles.

De modo geral, entre os entraves, mais explícitos, para a utilização das Tic's, que puderam ser observados estão: a falta dos recursos materiais - TVs, computadores, 
internet; a dificuldade de acesso a esses recursos - por exemplo: a existência de somente uma sala com TV na escola; a reprovação por parte de alguns gestores do uso regular desses materiais.

\section{Considerações finais}

A irreversibilidade da presença das novas tecnologias de informação e comunicação no cotidiano da sociedade atual é um fato que merece maior atenção dos setores voltados para a formação do sujeito.

Faz-se necessário entender que a carência do conhecimento digital é hoje uma forma de exclusão. Embora o discurso de muitas das políticas educacionais defenda a inserção das novas tecnologias na formação dos estudantes da educação básica, esse discurso não tem se concretizado nas instituições escolares.

No Estado de São Paulo ao acessar o site da Secretaria de Educação e se deparar com os discursos sobre o uso das Tic's tem se a impressão de que estas são uma constante no cotidiano das escolas.

A análise desenvolvida por esta pesquisa mostrou que, ao menos na cidade de Franca, essa primeira impressão está bastante equivocada. A quase ausência do uso pedagógico das novas tecnologias nas salas de aula analisadas chama a atenção para o quanto estamos distantes de atender a essa demanda irreversível.

Causa preocupação saber que mesmo o que seria um primeiro passo nesse sentido, ainda não é realidade nas escolas estaduais paulistas, uma vez que foi verificado que a promoção de estrutura física, ou seja, dos recursos materiais, ainda deixa muito a desejar.

Ainda que esta pesquisa tenha trabalhado com uma pequena amostra, fica evidenciado que a carência em relação ao desenvolvimento do conhecimento digital nas escolas estaduais paulistas é um problema que precisa ser debatido e enfrentado sob o risco de se aprofundar cada vez mais as desigualdades já existentes nos processos de formação para as diferentes camadas sociais. 


\section{THE TECHNOLOGY AS ALLIED IN HISTORY TEACHING AND YOUR MEMBERSHIP IN BASIC EDUCATION SCHOOLS}

ABSTRACT: This research sought to learn the use of information and communication technologies in public basic education in the state of São Paulo, specifically in relation to the teaching of history. There has been a historical context defense of the use of these technologies in educational institutions. The survey of qualitative data on the use of these resources was to cut the city of Franca and with the participation of students in the fourth year of the History of UNESP-France. Is learned from the analysis that despite the extensive literature on the advantages of using technology to the teaching of history in basic education classes and also the strong defense in relation to the use of these resources by the Secretariat of São Paulo State Education; the practical reality of educational institutions still is rooted in an educational process that is restricted essentially the figure of the teacher and the textbook, or the learning of reference provided by the state.

KEYWORDS: Education. Technology. Teaching activities.

\section{REFERÊNCIAS}

\section{BRASIL. Constituição (1988). Constituição Federal da República Federativa do}

Brasil. 1988. Disponível em:

http://portal.mec.gov.br/setec/arquivos/pdf_legislacao/superior/legisla_superior_const.p df. Acesso em: 10 fev. 2015.

IBGE. Instituto Brasileiro de Geografia e Estatística. Notícia Pnad 2013:

internet pelo celular é utilizada em mais da metade dos domicílios que acessam a Rede. Brasília: Senado Federal, 2013. Disponível em:

http://saladeimprensa.ibge.gov.br/pt/noticias?view=noticia\&id=1\&busca=1\&idnoticia= 2876. Acesso em: 10 fev. 2015.

BURINI, D. As políticas públicas de inclusão digital e seu impacto no processo de democratização na sociedade da informação brasileira. In: FIDALGO, A.; SERRA, P. Visões disciplinares. Covilhã: Universidade da Beira Interior, 2005. p.89-94.

CARDOSO, A. M. P. Pós-modernismo e informação: conceitos complementares?

Perspectivas em Ciência da Informação, Belo Horizonte, v.1, n.1, p.63-79, jan./jun. 1996.

GIDDENS, A. As consequências da modernidade. São Paulo: Ed. da UNESP, 1991.

HARVEY, D. Condição pós-moderna. São Paulo: Edições Loyola. 1992.

KENSKI, V. M. Tecnologias e ensino presencial e a distância. Campinas: Papirus, 2003.

LÉVY. P. As tecnologias da inteligência: o futuro do pensamento na era da informática. Rio de Janeiro: Ed. 34, 1993. 
PALMA FILLHO, J. C. A política educacional do estado de São Paulo (1983-2008). In: CONGRESSO DA ANPAE - ASSOCIAÇÃO NACIONAL DE POLÍTICA E ADMINISTRAÇÃO DA EDUCAÇÃO, 2010, Ibero-Luso-Brasileiros. Anais... Disponível em: <http://www.anpae.org.br/iberolusobrasileiro2010/cdrom/>. Acesso em: 28 jul. 2010.

SCHMIDT, M. A. A formação do professor de história e o cotidiano da sala de aula. In: BITTENCOURT, C. O saber histórico na sala de aula. São Paulo: Contexto, 2002. p.54-66.

SILVA, M.; FONSECA, S. G. Ensinar história no século XXI: em busca do tempo entendido. Campinas: Papirus, 2007. 